科伦预审第（2018）201 号

\title{
重庆医科大学附属第二医院 伦理委员会
}

\section{科研项目伦理预审意见书}

\section{主要研究者姓名：胡婷}

审查项目名称: 肝再生增强因子在对乙酰氨基酚诱导的急性肝损 伤中的保护作用及机制

申报课题来源：国家自然科学基金委员会

所在科室：病毒性肝炎研究所

审查方式: 快速审查 版本号: 2.0

提交日期：2018 年3月 13 日

经伦理委员会审查, 项目所提交的研究方案等资料符合医学 伦理原则和赫尔辛基宣言的各项要求, 研究设计符合相关法律、 法规。同意该项目的研究方案设计, 同意该项目经我院申报。

重庆医科学附属第二医院

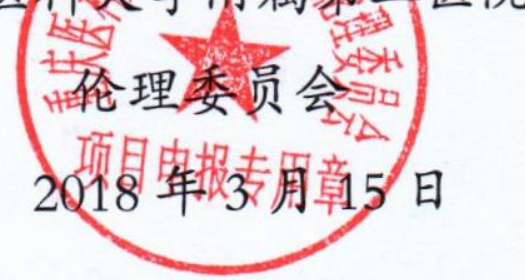

